\title{
INTEGRATION OF REAL-TIME DATA IN BIM ENABLES FM PROCESSES
}

\author{
NADINE WILLS \& JOAQUIN DIAZ \\ Technische Hochschule Mittelhessen, University of Applied Science, Germany
}

\begin{abstract}
Computer aid in Facility Management (FM) has been in use for about 40 years and has led to the so-called Computer Aided Facility Management (CAFM). CAFM offers various interfaces to exchange information between different kinds of tools. Various inter-trade organisations and associations have already developed information-exchange procedures. Besides the CAFM-developer, these organisations have defined information-exchange standards to integrate the Building Information Modeling (BIM) approach into FM, e.g. 3D visualization and underlying information concerning buildings and its devices. At this juncture (March 2017) the combination of BIM and FM is not only possible, it is mandatory. It is merely possible to exchange already existing information concerning the buildings. This implicates the acquisition and also adding the exchange of these information through to the chosen CAFM and BIM software tools. According to the fact that already existing information can only be used for the information exchange (and are later usable in FM), it is not possible to represent information which are related close to real-time. "Operating instead of reacting" is often used as a maxim in industry which leads to the integration of BIM and FM. The need of linking real-time data in FM is based on the requirement in the fields of energy management, central building control and safety systems. Via static and mobile sensors, information is collected and sent to CAFM-connectors. Within these connectors, information concerning BIM-linked building parts are transferred to an external database, which offers information management by the building participants, such as the architect, experts, project manager, building coordinator, investor and structural engineer. While using real-time data systems, lifecycle costs will decline while the whole life period of the building will increase, and safety for users will improve.
\end{abstract}

Keywords: integration, FM, CAFM, BIM, real-time data, data exchange.

\section{INTRODUCTION}

The interaction of Facility Management (FM), Computer-Aided Facility Management and Building Information Modelling has been extensively studied in recent years. Hochschule für Technik und Wirtschaft Berlin (University of Applied Science) developed a system that is able to manage information of geodata and Building Information Modeling (BIM) within FM. Data are collected in the form of geodata transformation out of already existing CADvisuals of areas. These data are managed by and provided integration-platform of heterogenous data sources which include geodata and BIM [1]. Another project of this University of Applied Science aims at the prevention of facility break-ups during the technical approval and servicing. Real and virtual information are linked by "Augmented Reality". Virtual models are provided via BIM. This tool also tries to release information in an intuitive and context-based form. Furthermore, data acquisition and supplement will be possible in-situ. Michael May and his team search for simplifying FM processes as well as a better integration of mobile terminals into workaday life [2]. Another study figures out, that BIM is within the whole lifecycle of a building. Moreover, BIM activities have switched from common planning and construction phase to the FM business. BIM can be regarded as a process which connects all participants of a project [3].

FM is a supporting management process for secondary-core processes of enterprises [4]. FM serves enterprises to fulfil its core business without a loss of capacity (time, finance or staff) while taking care of these secondary processes. GEFMA defines the requirements of 
FM as: support of the business core processes, an increase of workplace effectivity, verification of safety and occupational health, preservation of building and plant-engineering data, compliance of legal conditions and increase of usability quality as well as decrease of utilization costs [4]. Computer Aided Facility Management (CAFM) supports FM on the user-side. CAFM-software is a user-software, which supports facility processes within the whole life cycle of facilities. The reduction of alphanumeric and graphic data as well as the systematic regulation of workflow-management processes are basic tools of CAFM software. CAFM is the realization and support of the FM concept by means of modern information and communication technology. Moreover the terminus "Workplace Management System" is used in connection with CAFM [4], [5].

In contrast to the supporting CAFM tools, BIM is used especially in the planning and building process of facilities. The German Federal Ministry of transport and digital infrastructure specifies BIM as a cooperative method of operating, in which digital models of buildings and infrastructures form the basis. By this method of operating, each relevant information concerning building's lifecycle are summarized and managed before a transparent communication between all parties takes place [6]. In contrast to CAFM, BIM is not a software but a method of operating as part of an integral planning methodology [6]. The method of BIM includes the idea to found a continuous information exchange between all participants, which are connected with the facility, within the whole building lifecycle to reduce the loss of information and mistakes within data exchange. As a result of this, FM productivity can increase [7]. It is frequently assumed, that real-time data is a possibility to widen the range of FM businesses. So far, nearly exclusively industry disposes real-time data. Real-time data means to make information available for each participant of value-added chains by linking up. In dependence on "industry 4.0" real-time reproductions of all relevant processes are available. As a result of this process the goal is a connection of virtual and real objects [7].

\section{METHODOLOGY}

First of all, the authors studied the problems of BIM, CAFM and Real-Time Data before the research into these three parts as well as into Information-Exchange Systems started. After the researches have been done, the installation of Real-Time into BIM as well as into FM became proofed. Various attempts to combine both installation systems were made. Last but not least, possible complexities, e.g. the missing experience of combination systems and the technical integration are regarded.

\section{CURRENT SITUATION}

The origin of the term Computer Aided Facility Management (CAFM) is in the early 1960s to 1970 s, when architects and engineers began to build up rudimentary databases to use CAD-based programs [8]. CAFM is a process within the Facility Management sector that became developed concerning the sector's requirements and using the progress of "Web-generation" of 20th century [8]. CAFM-Ring is a German inter-trade organisation and association that improves the quality in information technology. Construction processes and the management of building information within the facilities' lifecycle are supported. Enterprises and individuals of the FM and CAFM businesses can apply for the membership in CAFM Ring e.V. The association is interested in supporting scientific studies that reach for a better understanding of CAFM and its advancement. Moreover, the association holds meetings with representatives of the sector to improve the intercommunication [10]. 


\subsection{CAFM-exchange systems}

As can be seen from the CAFM-Ring, the use of computer aid in the area of Facility Management is in use since about 40 years. CAFM offers various interfaces to exchange information between different kinds of software and tools. The interoperability of different software systems within a building's lifecycle is important so different participants can work within the same system. The collaboration with members of the real-estate sector develops and refines information-exchange systems. Moreover these systems become offered at the market exempt from charges [10]. The inter-trade organisation CAFM-Ring has already developed various information-exchange systems:

- CAFM-Connect 1.0 has been available since March 2011. The tool is able to exchange room information which are linked to the property, building, floor and room [11].

- CAFM-Connect 2.0 has been available since March 2015. This update of the already existing tool is able to provide the same results as the version Connect 1.0. Moreover it is possible to exchange information of technical facilities, e.g. building services (such as ventilation systems), safety-related elements or infrastructure assets (such as furniture) [11].

- A third version was in Beta-Phase until 31 March 2017. CAFM-Connect 3.0 provides the detention and transport of GEFMA $198^{2}$ related documents. Fig. 1 shows the intention of the CAFM-Connect System [11].

As it can be seen by the figure, sensors send real-time information concerning the building's constitution to BIM. The CAFM-Connect interface receives the information of BIM as well as area data, technical building equipment information and documents. This information can become transformed so that it is usable for FM.

During CAFM is already in steady use while working in Facility Management (especially in the utilisation phase of the building), BIM is usual only used within the planning phase and not within the utilisation phase. The status quo of BIM in combination with Facility Management is that it is not yet established. The reasons for this are open responsibilities and liabilities. A holistic point of view concerning the whole property lifecycle has not been carried out [3]. Various providers, e.g. Archibus, hold the view that BIM can be useful for Facility Management, too. The benefit of using BIM within FM is an improvement of the used floors (e.g. room classification, room reservations or furniture). Another benefit using

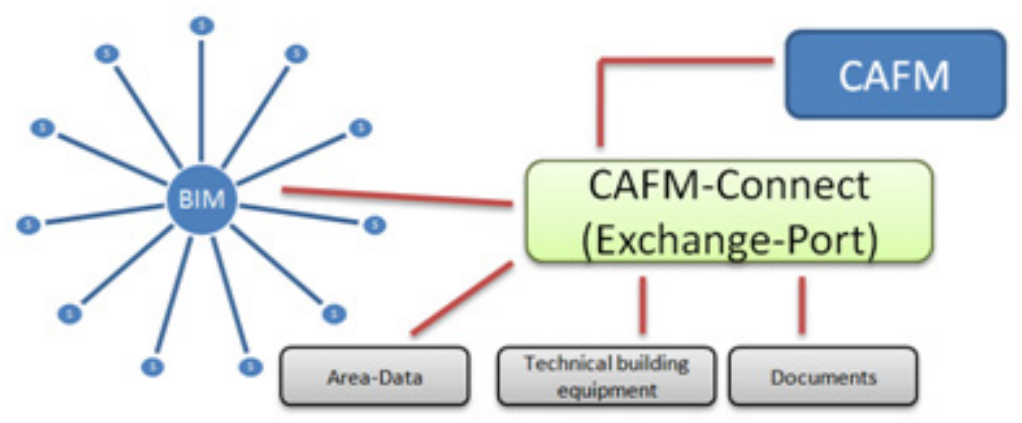

Figure 1: Working process of CAFM-Connect [13]. 
BIM within FM is in an improvement of the organisation of Business Processes, e.g. the reservation of rooms, the room ticketing as well as monitoring via IoT sensors. Service and repairs can benefit from the use of BIM in FM as well as installations, equipment and devices [3]. The bigger part of the enterprises argues, that the use of BIM within in FM can be seen a process which encourage the project's participants (architect, experts, project manager, building coordinator, investor and structural engineer) to work with the same system, so that the data are available for each participant at every tie without restrictions [3].

Various workshops hold meetings on the benefit of the use of BIM in FM. Ulrich Glauche [12] points out that the analysis of basic rules, such as EU guidelines, laws of the federal law, federal state law, and legal compensation insurance as well as technical laws of public committees and other restrictions have been indispensable to introduce BIM to FM. For the correct service of building and technical machinery, data and documents are required. The analysis of basic and special technical rules presents an overview of the required information for the use [12].

At this juncture (March 2017) the combined working with BIM and FM is possible, if the required information, data and documents become fixed and registered in advance. It is merely possible to exchange in advance registered information concerning the building. This implicates the acquisition and the adding of the data as well as the exchange of the data through to the chosen CAFM and BIM software. On account of the fact that only registered data can be chosen to become exchanged (and later become used for FM) it is not possible to picture data which are related close to real-time.

Nevertheless, building relevant information are only exchangeable if they become collected and integrated into the system before using. As result this means, that participants of the project ca use information of the past, even if the past means a short time period of, for example, a day or a few hours. Information concerning the current building mood cannot be used in this version.

\section{INTEGRITY OF BUILDING INFORMATION FOR REAL TIME MANAGEMENT}

As already mentioned above, "operating instead of reacting" is an often-used maxim in enterprises. As an example, car industries or component supplier use systems such as RFID to improve their production skills concerning the time of reaction. These RFID-tags are like sensors that enable the optimization, the control of production tasks and therefore the decision support.

\subsection{The use of static information as a basis for real-time acting}

The fact that only actual information are used in FM leads to a reaction of the FM participants whereas actions in front of necessary reactions would be more useful. In the following, two examples will be given, to show the negative aspects of working with info in FM (without regarding the use of BIM): the room planning is an example for the use of static data in FM with a high potential of resource waste. Rooms that are usually used to place a large number of people (such as conference rooms, lecture halls, offices, etc.) are booked by persons or organisations. The planning officer blocks this area for the booked term of period. If the planning officer will not make a round to check, if the booked (and instead of this blocked rooms) are used by the booking person, no instrument of control exists. Often, the person who reserved the space does not report that the booked space is not needed any longer. The reserved areas are abandoned and resources are wasted. By not using the reserved areas, energy resources for creating the correct climatic conditions within the room as well as furniture resources for fitting up the room are wasted. Moreover other parties, which need to 
switch to other places, could have used the room. In extremely exceptional cases, more areas are build because the organisations report a lack of available areas/rooms/facilities. As a result of this, especially financial resources are invested to build up extra (but gratuitous) facilities. The problem in this example is because of missing real-time information. A real-time data system at this point is able to capture this room-specific information and provides it to all users.

The second example is more related to BIM in contrast to the mentioned example, which is more related to CAFM. Structural damages often stay unnoticed until subsequent damages appear. The reasons that the damages stay unnoticed are deficient or missing checks by responsible personal. Moreover, the damage can appear on places, which cannot be seen with the naked eye. BIM is usually used in the planning and carry-out phase, not in the running phase. While facilities are newly constructed, few damages are reported. Especially old facilities are susceptible for damages. All-embracing information as well as real-time information are necessary to guarantee the maintenance of equipment regarding the prospective utilisation of the facility. The problem in this example is the missing possibility of real-time information access. If real-time systems are installed and linked to BIM planning tools, damages can be realized in the moment of appearance.

Regarding the mentioned examples, real-time data systems are necessary to receive up-to-date information concerning the facility. Therefore, it is negligible if the information pertains to real-estate management (e.g. room/area booking), building management (e.g. structural damages) or plant safety (e.g. fire protection).

\section{INSTALLING REAL-TIME INFORMATION SYSTEMS}

To improve the operating processes within FM and ensure long facility lifecycles, real-time information systems need to be installed. When communication-systems discharge qualitative and temporal requirements within the data exchange of a component's special application, the component is real-time compatible [9]. To look at this aspect in it's entirely, sensors need to be installed within the facilities. These sensors are part of the installed real-time data systems. Concerning building parts of the facilities, these sensors are integrated in the different construction elements (e.g. storefront, roof, windows, doors and other). The sensor is programmed to capture the functioning element-condition. If modifications in this condition occur, the sensor steps in the real-time information system which at least serves the information about the condition change to the headquarter. By this, the reason for the signal can become analysed by the responsibilities. Fig. 2 shows the working real-time information exchange process.

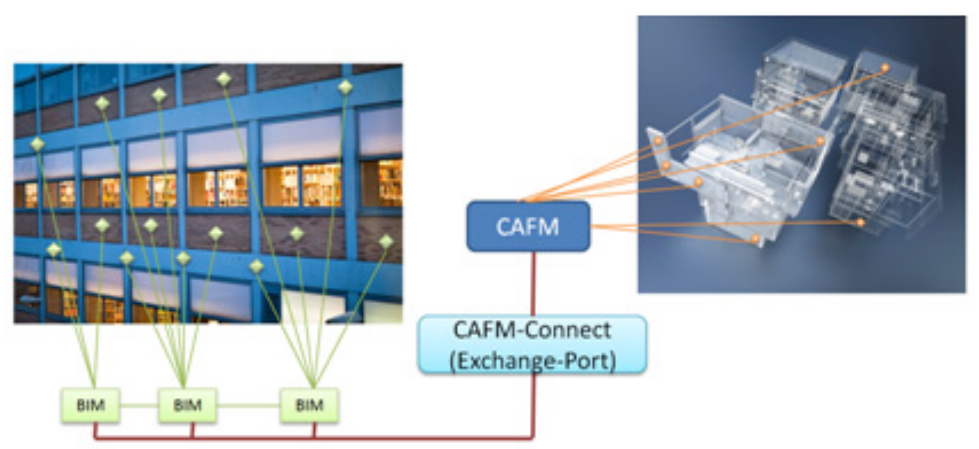

Figure 2: Real-time information system without error [14], [15]. 
As it can be seen by Fig. 2, the real-time sensors, which are situated at any place in the facility, send information to the BIM interfaces. These BIM interfaces transfer the information to the CAFM-exchange port. At this place, the information become transferred into FM-usable data and linked to the sensor's FM counterpart.

If a sensor realizes an abnormal condition, this information is real-time transmitted through the CAFM-Exchange Port into the CAFM system. The headquarter can than directly check, which sensor triggered the condition and can watch in the 3D building model in which area the problem exists.

Fig. 3 shows the operating process when an abnormal condition is realized.

\section{CONCLUSION}

The introduced systems need to become examined, tested and proofed. Therefore, it is necessary to have a look at different industry sensor systems. In particular, an Australian sensor system, which works as a presence detector seems to be interesting; the sensors notice if the room is being used or not. If the booked area is not used, the sensors send a signal to the headquarters which promptly resets the area into the original condition (heating, conditioning, etc.). The technical elaboration of this sensor systems needs to be fulfilled.

Moreover, both systems (BIM and CAFM) are highly developed if they are regarded particular. There are no researches available concerning the combination of both systems.

\section{FUTURE EXPLORATORY FOCUS}

In the future, real-time data systems which are compatible with BIM and CAFM tools, need to be examined, tested and proofed. This paper is not a technical elaboration of the real-time information system for BIM and FM but a processing of the integration question.

A positive aspect, which strengthens and enables the integration of BIM in FM is the advanced development status of BIM and FM respectively regarded and specified. Both systems are high developed and integrated in inter-trade organisations and associations. By this, both systems' acceptance in the industry has occurred. Never the less, an integration's weakness can be, that both systems command on high quality development levels but have not yet worked together. No research concerning the effects of BIM integration within FM processes has been instigated and no field reports are available. Regardless, it is possible that on both-side positive status of development a well-working symbiosis will appear. The risk

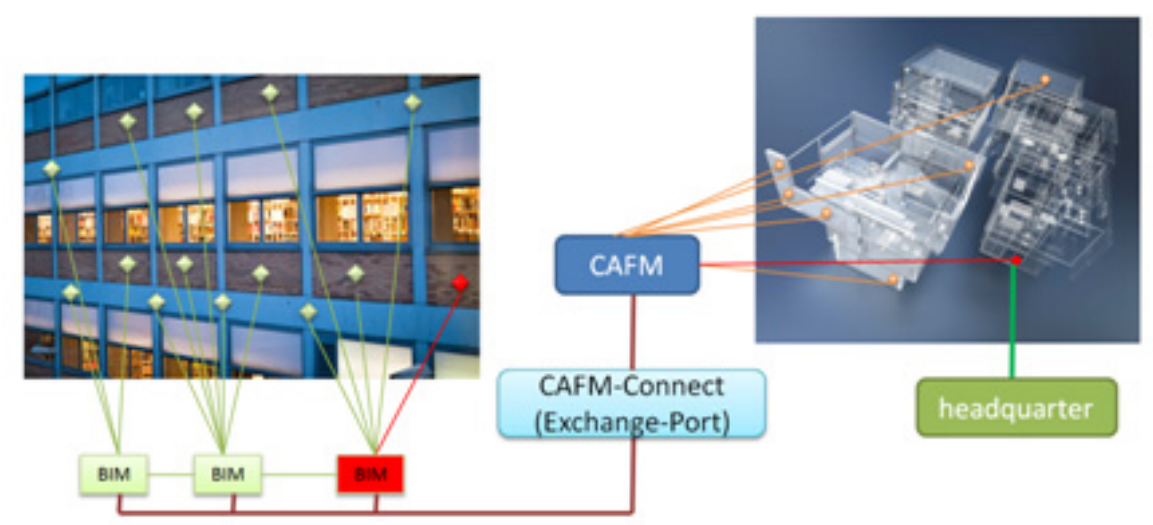

Figure 3: Real-time information system in abnormal conditions [14], [15]. 
of BIM integration is a possible missing appreciation of the system within FM industries. There are no adequate studies available, if CAFM-provider on the one hand and FM industries on the other hand, will integrate new systems, such as real-time sensoring. Moreover, no details concerning the anticipated costs of BIM integration are available.

The paper's authors will do research in the in financial aspects of the real-time data systems for the Facility Management sector. Therefor the investment cost of different sensor systems as well as installing costs need to be regarded.

\section{REFERENCES}

[1] Krämer, M., ArcoFaMa-Datenmanagement von Geodaten und BIM im Facility Management. 13 $3^{\text {th }}$ BIM-Anwendertag HTW Berlin, Berlin, Germany, 2015.

[2] May, M., BIM in der Instandhaltung mit Augmented Reality. $13^{\text {th }}$ BIM-Anwendertag HTW Berlin, Berlin, Germany, 2015.

[3] Gärtner, A., Nutzen und Vorteile der Integration von BIM und CAFM- ein Praxisbeispiel. CAFM-Connect Forum 2017, Hamburg, 2 Feb. 2017.

[4] German Facility Management Association (GEFMA), Definition Facility Management, Bonn, http://www.gefma.de/definition.html. Accessed on: 15 Apr. 2017.

[5] German Facility Management Association (GEFMA), Computer Aided Facility Management CAFM, Guideline 400, Bonn, 2013.

[6] Van Treeck, C., Elixmann, R., Rudat, K., Hiller, S., Herkel, S. \& Berger, M., Gebäude. Technik. Digital. Building Information Modeling, Springer Verlag: Heidelberg, 2016.

[7] Obermaier, R., Industrie 4.0 als unternehmerische Gestaltungsaufgabe. Betriebswirtschaftliche, technische und rechtliche Herausforderungen, Springer Verlag: Wiesbaden, 2016.

[8] May, M., CAFM-Handbuch: IT im Facility Management erfolgreich einsetzen. 3. Auflage, Springer Verlag: Heidelberg, S.12, 2013.

[9] Fraunhofer IESE, Begriffsdefinition: Echtzeitfähigkeit, Rechtzeitigkeit, Gleichzeitigkeit, http://www.software-kompetenz.de/servlet/is/28612/?print=true. Accessed on: 25 Apr. 2017.

[10] CAFM-Ring e.V. Branchenverband: Satzung des Branchenverbandes CAFM RING e.V., Wuppertal, 2016.

[11] CAFM-Ring e.V. Branchenverband, CAFM-Connect. Standardschnittstelle zum Austausch von Immobiliendaten. Wuppertal, http://www.cafmring.de/cafm-connect/. Accessed on: 28 Apr. 2017.

[12] Glauche, U., Die Agenda BIM im FM / Gebäudebetrieb. Nutzen von CAFM-Connect in Building Information Modeling-Einführung. CAFM-Connect Forum 2017, Hamburg, 2 Feb. 2017.

[13] CAFM Connect 1.0, 2.0, 3.0 - Sinnvolle und gängige Standards; Ambrosia FM Consulting \& Services GmbH, http://ambrosia-fm.de/ambrosia-compliance/ datenerhebungskonzepte/. Accessed on: 30 Apr. 2017.

[14] Fotogalerie Campus Gießen, Technische Hochschule Mittelhessen, https://www.thm. de/site/hochschule/campus/campus-giessen/fotogalerie-campus-giessen.html.

Accessed on: 29 Apr. 2017.

[15] Datenerfassung und Austausch mit CAFM-Connect nimmt weiter zu, CAFMRing e.V., http://www.cafmring.de/datenerfassung-und-austausch-mit-cafm-connectnimmt-weiter-zu/. Accessed on: 29 Apr. 2017. 